\title{
"É MELHOR SER SUPER-HERÓI DO QUE SER A VÍTIMA": UM ESTUDO SOBRE A PERCEPÇÃO DE ATLETAS E EX-ATLETAS COM DEFICIÊNCIA VISUAL SOBRE A COBERTURA MIDIÁTICA
}

\author{
'BETTER A SUPERHERO THAN A VICTIM': A STUDY ABOUT PERCEPTIONS \\ BY ATHLETES AND FORMER ATHLETES WITH VISUAL IMPAIRMENT ABOUT \\ MEDIA COVERAGE
}

\section{"ES MEJOR SER SUPERHEROE QUE SER LA VICTIMA": UN ESTUDIO SOBRE LA PERCEPCIÓN DE ATLETAS E EXATLETAS CON DEFICIENCIA VISUAL SOBRE LA COBERTURA DE LOS MEDIOS}

\section{Amanda Paola Velasco de Oliveira*, Bianca Natália Poffo*, Doralice Lange de Souza*}

Palavras chave: Esporte paralímpico. Transtornos da visão. Mídias sociais
Resumo: De acordo com vários estudos, os atletas paralímpicos tendem a ser retratados pelos veículos midiáticos ou como vítimas de suas deficiências e/ou como super-heróis/ supercrip. Diante disso, este artigo teve o objetivo de analisar a percepção de atletas e exatletas com deficiência visual sobre a forma com que eles são retratados pela mídia neste quesito. Realizamos uma pesquisa qualitativa, envolvendo entrevistas semiestruturadas e aprofundadas com cinco atletas e dois ex-atletas com deficiência visual. Verificamos que os entrevistados não se identificam como "coitadinhos" e não aprovam a vinculação da deficiência ao sofrimento. Verificamos também que não existe um consenso quanto à abordagem do super-herói/supercrip. Concluímos que a mídia não deve reproduzir uma perspectiva ou outra, pois estas não condizem com a realidade das pessoas com deficiência visual e tendem a perpetuar estigmas e preconceitos contra elas.
Keywords:

Paralympic sport. Vision disorders. Social medias.
Abstract: According to several studies, Paralympic athletes tend to be portrayed by the media as victims of their impairments and/or as superheroes/supercrips. This article analyzes the perception of athletes and former athletes with visual impairment about how they are portrayed by the media. We conducted a qualitative study involving semistructured and in-depth interviews with five athletes and two former athletes with visual impairment. We found that respondents do not identify themselves as "poor things" and do not approve of relating disability to suffering. We also found that there is no consensus on the superhero/supercrip approach. Our conclusion is that the media should not reproduce one perspective or another because they do not match the reality of people with visual impairment and tend to perpetuate stigmas and prejudices against them.
Palabras clave: Deporte paralímpico. Trastornos de la visión.

Medios de comunicación sociales.
Resumen: De acuerdo con varios estudios, los atletas paralímpicos tienden a ser retratados por los medios o como víctimas de sus deficiencias y/o como superhéroes/ supercrip. Frente a esto, este artículo tuvo el objetivo de analizar la percepción de atletas y exatletas con deficiencia visual sobre la forma en que son retratados por los medios. Realizamos una investigación cualitativa, consistente en entrevistas semiestructuradas y profundizadas con cinco atletas y dos exatletas con deficiencia visual. Constatamos que los entrevistados no se identifican como "pobrecitos" y no aprueban la vinculación de la deficiencia al sufrimiento. Constatamos también que no hay un consenso en cuanto al abordaje del superhéroe/supercrip. Concluimos que los medios no deben reproducir una perspectiva u otra, pues no condicen con la realidad de las personas con deficiencia visual y tienden a perpetuar estigmas y prejuicios contra las mismas.
* Universidade Federal do Paraná Curitiba, PR, Brasil. E-mail: amandavelasco.18@gmail.com; bia.poffo@ hotmail.com desouzdo@yahoo.com

Recebido em: 25/06/2018 Aprovado em: 01/11/2018

DOI: https://doi.org/10.22456/1982-8918.84237 (c) (i) () Licence c) (i) (8) Creative Commom 


\section{INTRODUÇÃOO}

Os Jogos Paralímpicos (JP) têm crescido em número de atletas, popularidade e notoriedade ao longo dos últimos anos. Eles ocorrem a cada quatro anos logo após a realização dos Jogos Olímpicos (JO), utilizando os mesmos locais e instalações destes. Os JP se constituem hoje em um dos maiores megaeventos do planeta e no maior evento esportivo destinado a pessoas com deficiência do mundo. Organizações ligadas ao Comitê Paralímpico Internacional (IPC - International Paralympic Committe) têm fomentado o desenvolvimento destes Jogos e lutado pela conquista de mais espaço midiático para eles. No caso do Brasil, 0 Comitê Paralímpico Brasileiro (CPB), logo após a sua criação, em 1995, passou a desenvolver estratégias para divulgar o esporte através de ações como o financiamento de viagens de jornalistas para cobrir os JP (MARQUES, 2010; MIRANDA, 2011).

Nos últimos anos, o CPB passou também a investir de forma massiva na circulação de informações e vídeos promocionais relacionados com o esporte paralímpico em redes sociais como o Facebook, Instagram e Twitter. Um dos resultados desses esforços, dentre outros, é que a cobertura midiática sobre os JP tem aumentado consideravelmente. Um exemplo disto foi verificado em um estudo de Santos et al. (2018) sobre a cobertura da Folha de S. Paulo, um dos jornais de maior circulação no Brasil. De acordo com os autores, enquanto durante os JP de Barcelona (1992) o jornal publicou apenas nove notícias sobre o evento, cobrindo uma área de $314,6 \mathrm{~cm}^{2}$ do periódico, durante os JP Rio 2016, este publicou 114 notícias, que corresponderam a $33.720,8 \mathrm{~cm}^{2}$. Embora esteja havendo um aumento quantitativo da cobertura do esporte paralímpico, existem, no entanto, algumas questões sobre a qualidade das notícias que precisam ser consideradas.

Alguns pesquisadores têm se debruçado a estudar a forma como a mídia vem realizando a cobertura do esporte paralímpico. Um importante achado destas pesquisas é que os atletas paralímpicos tendem a ser retratados ou como vítimas de suas deficiências e/ou como super-heróis. Na primeira abordagem, eles são vistos como "coitadinhos" por supostamente sofrerem devido à sua deficiência (FIGUEIREDO; GUERRA, 2005; GONÇALVES; ALBINO; VAZ, 2009; HILGEMBERG, 2014). Na segunda abordagem eles são vistos como superheróis, ou supercrips, por terem superado a sua deficiência e realizado feitos supostamente extraordinários "a despeito da deficiência" (HARDIN, HARDIN, 2004; SILVA; HOWE, 2012; MARQUES et al., 2014; MARQUES et al., 2015).

Verificamos, através de um levantamento prévio da literatura, que existe uma lacuna de discussões no que diz respeito às formas com que a mídia vem retratando atletas com deficiência visual em específico. A visão é um sentido primordial na relação social e pessoal dos indivíduos e é através da adaptação que as pessoas com deficiência visual estabelecem sua forma própria de perceber o mundo, baseada principalmente em referências sonoras e cinestésicas (MORATO et al., 2011). Dada essa particularidade das pessoas com esse tipo de deficiência, e considerando que, segundo o Censo realizado pelo Instituto Brasileiro de Geografia e Estatística (IBGE) em 2010, a deficiência com maior ocorrência no Brasil é a deficiência visual (ocorrência em $18,6 \%$ da população), desenvolvemos um estudo de cunho qualitativo voltado especificamente para o caso de pessoas com deficiência visual. 0 nosso objetivo foi analisar a percepção de atletas e ex-atletas com deficiência visual sobre a forma com que eles são retratados pela mídia. Dentre as diferentes temáticas que emergiram deste 
estudo, enfocaremos aqui as percepções dos participantes da pesquisa quanto à questão do "coitadinho" e do super-herói, uma vez que essas temáticas estão fortemente presentes na literatura que vem discutindo as formas com que a mídia produz notícias sobre os atletas com deficiência. A reprodução de preconceitos e estereótipos como esses em nada contribuem para a inclusão social das pessoas com deficiência.

\section{DECISÕES METODOLÓGICAS}

A pesquisa foi de cunho qualitativo e foi aprovada pelo Comitê de Ética em Pesquisa da Universidade Federal do Paraná, registro CAAE 55300216.5.0000.0102, parecer n. 1.574.202. Realizamos entrevistas semiestruturadas e aprofundadas com cinco atletas e dois ex-atletas de três modalidades paralímpicas: Goalball, Futebol de 5 e Atletismo. Selecionamos exatletas para participar da pesquisa a fim de trazer à tona questões pertinentes vivenciadas por eles na época em que praticavam esporte, traçando um paralelo com a realidade atual. A seguir apresentamos uma tabela com uma breve descrição dos participantes deste estudo:

Quadro 1 - Caracterização dos participantes da pesquisa

\begin{tabular}{|c|c|c|c|}
\hline Nome Fictício & Idade & Modalidade & Categoria \\
\hline Carlos & 47 anos & Atletismo & Ex-atleta \\
\hline Paulo & 59 anos & Atletismo/ Futebol de 5 & Ex-atleta \\
\hline Pedro & 38 anos & Goalball & Atleta Amador \\
\hline Marcos & 25 anos & Atletismo & Atleta Paralímpico \\
\hline Ana & 40 anos & Goalball & Atleta Paralímpico \\
\hline André & 27 anos & Futebol de 5 & Atleta Paralímpico \\
\hline Bruna & 38 anos & Atletismo & Atleta Paralímpico \\
\hline
\end{tabular}

Fonte: Dados da dissertação de Oliveira (2018)

As entrevistas foram realizadas no período de novembro de 2016 a fevereiro de 2017 e duraram em média 45 minutos cada. Elas foram realizadas presencialmente ou via Skype 1 , dependendo da localização geográfica dos entrevistados. Todas as entrevistas foram gravadas e transcritas na íntegra. $O$ roteiro de entrevista contemplou várias questões abertas sobre a opinião dos atletas a respeito da cobertura midiática. Após essas questões, mostramos a eles os seguintes vídeos exibidos em programas da Rede Globo: "Equipe feminina do Brasil ganha prata no revezamento 4x100 metros"2, exibido no programa "Jornal Hoje", dia 15 de setembro de 2016; "Clipe reúne grandes momentos dos Jogos Paralímpicos Rio 2016", exibido no programa "Esporte Espetacular", dia 18 de setembro de 2016; e o terceiro vídeo foi exibido no "Jornal Nacional", no dia 31 de agosto de 2012 e é referente aos Jogos Paralímpicos de Londres 2012. Também lemos uma reportagem intitulada "Unida ao irmão por doença, Regiane dá volta no destino para nadar no Rio", proveniente do portal de notícias da Rede Globo e divulgada no dia 12/09/2016. Selecionamos esses materiais porque eles ilustram algumas abordagens recorrentes e consideradas como problemáticas por outros pesquisadores que vêm discutindo

\footnotetext{
1 Estudos como o de Oliveira et al. (2010) e o de Braga e Gastaldo (2012) demonstram que o Skype tem se revelado uma ferramenta útil para a coleta de dados em pesquisas qualitativas, principalmente em casos que não é possível a interação "face to face" entre pesquisador e pesquisado.

2 Disponível em: <http://g1.globo.com/jornal-hoje/edicoes/2016/09/15.html>. Acesso em: 17 dez. 2018.

3 Disponível em: <https://globoplay.globo.com///5314814/programa/>. Acesso em: 17 dez. 2018.
} 
a cobertura midiática do esporte paralímpico. Queríamos verificar se os participantes de nossa pesquisa espontaneamente falariam sobre os supostos problemas desses materiais. Nos casos em que eles teceram comentários, investigamos como pensavam sobre 0 assunto. A utilização desses materiais foi vantajosa no sentido de nos permitir aprofundar algumas questões já discutidas na literatura. Por outro lado, reconhecemos que ela pode ter desviado um pouco a atenção dos entrevistados de outras questões que lhes eram caras e não apareceram nos vídeos e reportagem.

Realizamos uma análise temática (BRAUN; CLARKE, 2006), tomando como base características já apontadas na literatura como recorrentes da cobertura midiática do esporte paralímpico, tais como a representação de atletas com deficiência ou como super-heróis ou como vítimas, bem como uma ênfase exacerbada da deficiência em detrimento da trajetória esportiva dos atletas (FIGUEIREDO; NOVAIS, 2011; GONÇALVES; ALBINO; VAZ, 2009; HARDIN; HARDIN, 2004; MARQUES et al. 2014; MARQUES et al. 2015; PURDUE; HOWE, 2012; SILVA; HOWE, 2012). Também consideramos outros temas que emergiram dos dados e que ainda não aparecem em publicações sobre o tema. Ou seja, codificamos e categorizamos as passagens das entrevistas tanto de forma dedutiva (a partir dos autores) quanto indutiva (a partir dos próprios dados). Realizamos inicialmente uma análise individual das entrevistas com cada um dos participantes, observando temas que se destacavam em suas falas e que poderiam nos auxiliar a responder à questão central deste trabalho: qual a percepção de atletas e ex-atletas com deficiência visual sobre a forma com que eles são retratados pela mídia? $\mathrm{Na}$ sequência, realizamos uma análise cruzada das entrevistas para identificar quais temas eram recorrentes e relevantes no conjunto total de dados. Conforme apontamos anteriormente, no caso deste trabalho, nos focaremos apenas na discussão sobre as temáticas "coitadinho" e "super-herói".

\section{RESULTADOS E DISCUSSÃO}

Ou você é coitado ou você é súper! Na realidade, não somos nem uma coisa nem outra. Somos desafiadores como é todo e qualquer atleta! (Carlos, 47 anos, ex-atleta).

De acordo com os participantes do estudo, de forma consistente com os resultados de outras pesquisas, os atletas costumam ser apresentados pela mídia ou como vítimas das suas deficiências ou como super-heróis que superam as dificuldades provenientes de suas deficiências e realizam feitos esportivos supostamente incríveis. A vitimização da pessoa com deficiência é uma forma de representação que, segundo os entrevistados, se manifesta tanto nos veículos midiáticos quanto na sociedade. Conforme afirma Carlos, logo abaixo, a pessoa com deficiência tende a ser automaticamente definida como sofredora:

Não é à toa que a sociedade trata com pena, trata com pieguice, trata com um dó, que é um dó que parece insuperável. $E$ isso você vê todo tempo se você parar para ler as entrelinhas de uma matéria. $A$ maioria das vezes que você vê é isso: 'A pessoa sofre, mas ela superou', porque se coloca como uma condição atinente à deficiência, o sofrimento (Carlos, 47 anos, ex-atleta).

Vários estudos que analisaram o conteúdo midiático demonstram que os atletas com deficiência tendem a ser tratados como sofredores e coitadinhos (FIGUEIREDO; NOVAIS, 2011; GONÇALVES; ALBINO; VAZ, 2009; HILGEMBERG, 2014). Hilgemberg (2014), por 
exemplo, analisou em algumas mídias impressas brasileiras e portuguesas quais estereótipos estiveram associados aos atletas paralímpicos no período dos Jogos Paralímpicos de 1996 (Atlanta), 2000 (Sydney), 2004 (Atenas) e 2008 (Pequim). De acordo com a autora, a vitimização das pessoas com deficiência está associada ao interesse de despertar sentimentos de compaixão e caridade nos espectadores. Além disso, a autora constatou a utilização recorrente de estereótipos como o de que a pessoa com deficiência é triste, ou de que a deficiência é uma doença que causa sofrimento.

Vale citar a opinião de outra participante de nosso estudo sobre a questão da vitimização do atleta com deficiência:

Quando as pessoas vinculam isso [que a pessoa com deficiência sofre e é coitadinha] na mídia, como eu te falei, dá a impressão que eles vinculam como se todas as situações, como se fosse um determinismo, né? Nasceu deficiente, pronto! Sofreu e é coitadinho. E isso não é verdade! Você vai encontrar as duas situações! (Ana, 40 anos, atleta paralímpica).

De acordo com a entrevistada, em todos os grupos com alguma característica em comum (ex. idosos ou pessoas com deficiência) existirão pessoas acomodadas e pessoas que buscarão se autodesenvolver e buscar novas oportunidades na vida. Também existirão indivíduos dependentes e que passarão a vida sofrendo, bem como existirão aqueles que serão felizes, buscarão a sua independência e buscarão conviver bem com a sua realidade.

De acordo com André, as ideias distorcidas e os preconceitos que se têm das pessoas com deficiência estão relacionados com a falta de conhecimento sobre a realidade dessas pessoas:

As pessoas que não conhecem [pessoas com deficiência], têm esse preconceito. Acham que são coitadinhos, acham que a gente não pode fazer nada, que depende das pessoas para tudo, até para coisas simples como tomar um banho, escovar um dente, né? (André, 27 anos, atleta paralímpico).

Cambruzzi (2011) destaca que o preconceito, na maioria das vezes, está ligado a atitudes de caráter comiserativo e que as atitudes preconceituosas são consequência de uma leitura distorcida da deficiência. $O$ desconhecimento é um elemento fundamental na construção de estigmas e estereótipos. Neste contexto, a mídia possui um potencial de tornar familiar o que é desconhecido, colaborando para a disseminação da informação e aceitação da deficiência (AMARAL, 1994).

O desconhecimento acerca do potencial das pessoas com deficiências e o preconceito de que não são capazes de realizar determinados feitos, por vezes, ocorre dentro da própria família, como é possível observar no depoimento a seguir:

\footnotetext{
Antes dele [o meu pai] começar a conviver com o esporte paralímpico e de alto rendimento como ele vive, ele tinha até a visão minha como coitadinho. Porque ele achava que eu não poderia fazer as coisas (Marcos, 25 anos, atleta paralímpico).
}

Marcos relata que até o momento em que começou a praticar um esporte, o seu pai o percebia como um coitado e questionava as suas capacidades. A convivência com o esporte paralímpico modificou a percepção desse pai, que, por sua vez, passou a reconhecer as potencialidades e possibilidades não só de seu filho, mas também de outras pessoas com deficiência. 
Um dos atletas entrevistados revelou que compete em provas convencionais (para pessoas sem deficiência) e que tende a vencê-las. No entanto, sente que o seu mérito esportivo e as suas capacidades são menosprezadas pela mídia local, que tende a insinuar que ele vence porque possui algum tipo de vantagem sobre os outros competidores:

\section{Eu vejo que, por mais que eu faça além dos atletas olímpicos aqui, eu ainda sou cotado muito como coitadinho pela mídia [...], como se eu tivesse tido alguma vantagem por ser deficiente visual. Como se eu tivesse largado na frente ou obtido alguma vantagem. E não! Porque quem está na prova, a gente sabe que não é verdade. Os atletas aqui, todo mundo sabe que não é verdade. Que eu corro em condições iguais ou até piores que eles e venço a prova! (Marcos, 25 anos, atleta paralímpico).}

Encontramos em um jornal online uma notícia sobre a participação do Marcos em uma prova de corrida que bem ilustra o que ele diz acima. Na notícia intitulada "Atleta Paralímpico de Sidrolândia é o ganhador da 4⿳亠 Corrida Cross Country", o texto começa falando sobre 0 atleta vencedor da corrida e logo em seguida diz o seguinte:

Para o feito, porém, [...] contou com a ajuda do seu amigo e segundo colocado na classificação geral, Leonardo da Silva Messias, de 30 anos, ele chegou ao lado de [...] no ponto final da prova, mas preferiu deixar o primeiro lugar para 0 amigo (NOTICIDADE, 12 mar. 2017) ${ }^{4}$.

O uso do advérbio "porém" no início do trecho transmite a ideia de que Marcos não poderia ter vencido se 0 outro atleta não tivesse 0 deixado chegar primeiro. Talvez isto tenha sido verdade. No entanto, como o jornalista não cita nenhuma evidência de que esse fato tenha realmente ocorrido, fica a impressão de que ele chegou a essa conclusão sozinho, provavelmente baseado em um preconceito de que a pessoa com deficiência normalmente precisa de auxílio para que obtenha sucesso.

A forma com que a mídia retrata as pessoas com deficiência tem contribuído para a perpetuação de mitos sociais sobre a deficiência (SILVA; HOWE, 2012). A mídia exerce um papel fundamental na construção do imaginário da sociedade em relação à pessoa com deficiência. As ideias por ela veiculadas tendem a ser percebidas como verdadeiras pelo público em geral, mesmo quando elas não condizem com a realidade (MARQUES, 2016). Como uma parcela significativa da sociedade só tem acesso a determinadas informações através dos conteúdos veiculados pela mídia e esta é uma importante formadora de opiniões a respeito da realidade das pessoas com deficiência, o conteúdo transmitido por ela pode influenciar de forma positiva ou negativa na forma como as pessoas com deficiência serão vistas pela sociedade (HILGEMBERG, 2014).

De acordo com uma de nossas entrevistadas, a mídia tem tratado o atleta como vítima como estratégia para melhor atrair a atenção do público e "vender" o seu produto:

Então, se acontece alguma coisa ruim, não ruim, mas alguma coisa que vitimiza, é mais fácil do que às vezes você mostrar que ganhou medalha ou que conquistou alguma coisa. Esse [último] tipo de história nem sempre vende! (Bruna, 38 anos, atleta paralímpica).

A mídia tem buscado estratégias para atrair o interesse do público, tornando-o um produto consumível e rentável tanto para ela (HOWE; JONES, 2006) quanto para o conglomerado de empresas que a patrocina (PIRES, 1998). A vitimização dos atletas paralímpicos ou a ênfase

40 nome do atleta foi suprimido do trecho da reportagem para que sua identidade fosse preservada. 
dada à deficiência dos atletas nas notícias tem sido uma destas estratégias (HILGEMBERG, 2014; PURDUE; HOWE, 2012). Isto, por consequência, tende a baixar ainda mais as expectativas que se tem das pessoas com deficiência. $O$ relato a seguir mostra como esta estratégia pode repercutir na vida cotidiana de pessoas com deficiência visual:

Você vai numa pizzaria, você chega lá e senta para comer uma pizza, todo mundo fica te olhando para ver se você vai acertar a boca. Aí dali a pouco você corta a pizza certinho, o outro acha que aquilo é fantástico, entendeu? É culpa da mídia. A mídia deveria colocar as pessoas com deficiência como pessoas normais (Pedro, 38 anos, atleta amador).

Conforme afirma Pedro, tende-se a duvidar que uma pessoa com deficiência visual consiga "acertar a boca" sem estar enxergando o garfo. Ao conseguir desempenhar esse ato, ela é percebida como se tivesse "super-habilidades", quando, na verdade, ela é uma pessoa como qualquer outra, com a diferença de que possui uma deficiência sensorial. Com algumas adaptações, a pessoa com deficiência visual pode realizar tarefas cotidianas e viver de forma plena. Na citação acima, Pedro culpa a mídia pelo preconceito existente. No entanto, sabemos que a mídia não cria sozinha este tipo de ideia em relação à pessoa com deficiência. Isto é reflexo de uma sociedade que historicamente vem marginalizando e estigmatizando alguns grupos minoritários (GOFFMAN, 2008). Conforme explica Martin-Barbero (2009), os receptores das notícias são sujeitos ativos do processo de recepção no meio social em que estão inseridos, ou seja, são sujeitos que interagem, interpretam e reelaboram informações e imagens.

O exemplo de Pedro, bem como outros anteriormente citados, ilustra o que Le Breton (2006) define como "personificação da deficiência". Isto acontece quando o sujeito desaparece e é visto apenas pela sua deficiência. Este exemplo também condiz com o que Amaral (1998) chama de "generalização indevida", que ocorre quando existe uma "transformação da totalidade da pessoa com deficiência na própria condição de deficiência, na ineficiência global. O indivíduo não é alguém com uma dada condição, é aquela condição específica e nada mais do que ela: é a encarnação da ineficiência total" (p. 5). Ou seja, a pessoa desaparece e é vista apenas pela sua deficiência e pelo seu suposto impedimento.

De acordo com os nossos entrevistados, tal como a abordagem do "coitadinho", a abordagem do super-herói/supercrip tem também se feito presente historicamente na mídia. Vide por exemplo a seguinte citação:

No primeiro momento, o resultado de Sydney, acho que foi quando a mídia começou a retratar mais o esporte paralímpico. Sempre foi um extremo de super-heróis [...] o que foi mostrado foi a ótica deles. E já foi mostrada uma ótica de superação extrema, de conquistas e de quebra de limites. E isso veio norteando as imagens até 0 tempo de hoje (Bruna, 38 anos, atleta paralímpica).

Alguns autores vêm estudando a questão do atleta paralímpico como super-herói/ supercrip (HARDIN; HARDIN, 2004; HILGEMBERG, 2014; MARQUES et al., 2014; MARQUES et al., 2015; SILVA; HOWE, 2012). Hardin e Hardin (2004), por exemplo, ao perguntarem a atletas como eles se sentiam a respeito dessa forma de personificação do atleta paralímpico, obtiveram opiniões controversas. Os atletas que aprovam o modelo do supercrip dizem que a criação de um super-herói com deficiência que venceu suas limitações poderia inspirar outras pessoas com deficiência a praticarem esportes. Igualmente, os atletas do estudo realizado por Silva e Howe (2012) afirmaram que o modelo supercrip pode ser positivo no sentido de gerar visibilidade e esperança para pessoas que lutam por aceitação social e maior espaço midiático. 
No estudo de Hardin e Hardin (2004), os atletas que discordam da abordagem do supercrip afirmaram que esta pode ser interessante para a mídia, pois é o que tende a impulsionar a venda das transmissões, bem como atrair o público, pois causa comoção e mostra como o ser humano é capaz de superar suas limitações, servindo de exemplo para a sociedade. Entretanto, muitos atletas paralímpicos não gostam do enfoque na superação de suas limitações resultantes da deficiência. Eles prefeririam que os seus feitos esportivos fossem destacados, uma vez que trabalham de forma árdua para competir e vencer em provas esportivas. Eles querem ser tratados como atletas de alto rendimento.

Assim como os entrevistados por Hardin e Hardin (2004), alguns atletas do nosso estudo relataram não gostar de serem retratados como super-heróis. Conforme explica Paulo, eles são apenas seres humanos que, como os atletas sem deficiência, se dedicam seriamente a um ou a outro esporte:

Nós precisamos colocar um pouquinho de menos superação. $O$ atleta, ele não é um súper, ele é um atleta. Ele é uma pessoa com deficiência que está participando em uma competição onde o objetivo é o da vitória, o objetivo é sempre treinar mais e ele vai se dar melhor. Então não precisamos dar a qualificação de súper, de heróis. São atletas, são seres humanos [...]. Essa supervalorização de determinadas coisas me incomoda um pouco, sabe? Me incomoda porque os atletas com deficiência, ninguém quer ser super-herói. 0 atleta é 0 atleta [...] Ele é sem dúvida um herói porque ele participa, porque ele compete. A mais, aquele que não é deficiente e que participa de jogos olímpicos, é tão herói quanto! (Paulo, 59 anos, ex-atleta).

Paulo prossegue afirmando que todo atleta, independentemente de possuir deficiência ou não, passa por adversidades nos treinamentos e nas competições. Dessa forma, ele não se sente à vontade com a ênfase de super-herói dada ao atleta com deficiência, pois os atletas que não possuem deficiência também passam por adversidades para chegar ao maior evento esportivo do mundo, que são os Jogos Olímpicos e, na visão de Paulo, esses atletas não recebem a mesma ênfase na superação de dificuldades que os atletas paralímpicos recebem. Não podemos esquecer, contudo, a recorrência de histórias de superação veiculadas na mídia de atletas do esporte convencional. Helal, Cabo e Marques (2010), por exemplo, analisaram a cobertura jornalística realizada pelos jornais $O$ Globo e Lance! sobre os Jogos Pan-Americanos do Rio 2017 e verificaram fenômeno similar.

Ana também pensa que os atletas com deficiência não querem e não devem ser transformados em super-heróis. Ela reitera que, ainda que ela possua mais limitações físicas e sociais do que as pessoas sem deficiência, isso não a impede de ir em busca da realização daquilo que almeja. A entrevistada também afirma que quer ser vista como um exemplo de determinação por superar diariamente as suas limitações, mas não como uma superheroína, pois não faz nada de extraordinário para ser retratada dessa maneira:

Eu não sou uma super-heroína. É o que eu estou sempre tentando dizer. Não existe essa súper: 'Ó, eu sou uma heroína!'. Não, não sou. Mas eu sou uma pessoa que, sim, eu supero limites. Sim, eu tenho mais dificuldade que as outras pessoas. E mesmo assim eu corro atrás! (Ana, 40 anos, atleta paralímpica).

Pedro tem a mesma opinião de Paulo e de Ana em relação a ser mostrado como um super-herói. Para ele, os atletas paralímpicos não são super-heróis. Eles são pessoas comuns que praticam diferentes atividades, e dentre elas, um esporte. 0 diferencial é que as pessoas 
com deficiência tendem a enfrentar mais dificuldades. Enfrentam não somente dificuldades físicas, mas também a falta de oportunidades em diferentes esferas sociais:

Nós não somos super-heróis. Somos seres humanos comuns, normais. Com limitações às vezes diferentes de vocês, ditos normais, que também têm limitações [...]. Aí quando a gente consegue chegar lá sem as mesmas oportunidades que os outros, eles falam 'Ah, foi um super-herói. Não, não foi um super-herói. A gente só sofreu um pouco mais (Pedro, 38 anos, atleta amador).

A fala de Pedro ilustra uma justificativa do porquê a sociedade transforma as pessoas com deficiência em super-heróis ao vê-las realizando algo. Conforme Silva e Howe (2012), há uma tendência em subestimar ou superestimar as conquistas, sempre que a deficiência está presente. Muitos possuem uma baixa expectativa sobre as potencialidades das pessoas com deficiência (HARDIN; HARDIN, 2004). Desta forma, qualquer ação positiva tende a gerar admiração e elogios (SILVA; HOWE, 2012).

Em contraposição à percepção de que os atletas paralímpicos fazem apenas o que atletas devem fazer para chegar ao pódio, alguns entrevistados consideram aceitável a ideia de que os atletas com deficiência sejam retratados como super-heróis, pois eles de fato precisam constantemente superar determinadas dificuldades físicas, ambientais e socioculturais devido às suas deficiências. Para André, os atletas paralímpicos se superam diariamente ao desmistificar a concepção de que as pessoas com deficiência são intimamente dependentes de outras pessoas:

Sei lá, acho que a gente se sente um pouco mesmo super-herói por causa de superar toda a dificuldade. Porque 0 que as pessoas esperam de pessoas com deficiência? Que elas fiquem em casa, que não façam nada, que sempre precisam de outras pessoas. E a gente não, a gente todos os dias procura lutar, procura superar essas dificuldades e encarar a vida, né, à nossa maneira. De um ponto de vista, é como se fosse um super-herói mesmo, né? (André, 27 anos, atleta paralímpico).

André se sente um super-herói na medida em que supera as adversidades provenientes da deficiência. Pelo fato de o atleta estar buscando superar as suas limitações diárias, lutando para vencer a falta de oportunidades, as barreiras sociais e arquitetônicas que uma pessoa com deficiência normalmente precisa enfrentar para viver, o entrevistado concebe a si e a todos os atletas com deficiência o título de super-heróis.

Bruna também prefere ser retratada como uma super-heroína ou como uma pessoa extraordinária, do que ser tratada como "coitadinha" ou vítima da deficiência:

Eu prefiro me ver dessa maneira [como uma super-heroína], do que me ver como uma coitadinha, que não conseguiu. Eu prefiro, eu pelo menos, penso que vale a pena ser super-herói. É melhor ser super-herói do que ser a vítima! (Bruna, 38 anos, atleta paralímpica).

O tratamento de atletas paralímpicos como super-heróis pode ser percebido de forma positiva ou negativa, dependendo do caso. Por um lado, ele pode desmistificar a ideia de que as pessoas com deficiência são "coitadinhas". Por outro lado, ele pode gerar problemas na medida em que enfatiza o esforço individualizado do atleta como se o sucesso do indivíduo fosse fruto apenas de seu esforço pessoal (SILVA; HOWE, 2012).

A projeção de imagens de atletas paralímpicos como super-heróis e exemplos a serem seguidos pode ser uma fonte de frustração para as pessoas com deficiência que, embora com 
muita vontade e esforço, não consigam realizar os mesmos feitos devido a fatores que fogem de seu controle (HARDIN; HARDIN, 2004), como, por exemplo, o seu tipo e grau de deficiência, a falta de apoio da família, e as barreiras sociais, culturais, ambientais e financeiras. Nestes casos, a expectativa em relação à pessoa com deficiência que havia aumentado a partir de determinados exemplos de sucesso tende a diminuir, e o estigma de "incapaz" que a pessoa com deficiência carrega consigo pode retornar (HARDIN; HARDIN, 2004; SILVA; HOWE, 2012).

\section{CONSIDERAÇÕES FINAIS}

Esta pesquisa possibilitou que déssemos voz a atletas e ex-atletas com deficiência visual no que diz respeito a uma das formas com que a mídia normalmente trata os atletas paralímpicos, mais especificamente no que diz respeito à questão do "coitadinho" e/ou "superherói". Os nossos entrevistados não se identificam como coitados e não concordam com a projeção da ideia de que pessoas com deficiência são sofredoras, uma vez que isto não necessariamente condiz com a sua realidade e tende a fomentar preconceitos sociais.

Sobre a tendência de se tratar os atletas como super-heróis, ouvimos opiniões diversas. Alguns dos entrevistados relataram não gostar de ver atletas com deficiência serem retratados desta forma. Eles percebem estes atletas como atletas de alto rendimento que se dedicam aos treinos e que superam limitações como qualquer outro desportista sem deficiência. Outros entrevistados aceitam a ideia de que os atletas com deficiência sejam retratados como super-heróis, pois eles superam não somente as expectativas negativas a eles imputadas, mas também precisam cotidianamente enfrentar barreiras físicas, ambientais e socioculturais que costumam dificultar a vida das pessoas com deficiência. Todos concordam, no entanto, que a apresentação de atletas paralímpicos como super-heróis não é a ideal. Todos também concordam que é melhor serem tratados como super-heróis do que como vítimas.

Embora os resultados deste estudo não possam ser generalizados, eles sugerem que na perspectiva de alguns atletas e ex-atletas com deficiência visual, a mídia deveria enfocar mais a trajetória esportiva dos desportistas e as suas batalhas no campo esportivo do que as suas supostas tristes histórias de vida. São necessários outros estudos que incluam mais participantes com deficiência visual, envolvidos e não envolvidos com a prática esportiva para melhor explorar a temática aqui trabalhada. Seriam também interessantes outros estudos que considerassem as vozes de militantes de movimentos sociais organizados em prol dos direitos das pessoas com este tipo de deficiência, uma vez que estes possíveis interlocutores tendem a conhecer a realidade destas pessoas com mais propriedade do que aqueles não são tão engajados politicamente. Investigações desta natureza têm o potencial de gerar conhecimentos que podem contribuir para a qualificação da mídia na cobertura do esporte para pessoas com deficiência visual de forma mais justa e compatível com as suas capacidades e conquistas. Isto, por consequência, pode gerar um legado positivo não somente para indivíduos com deficiência envolvidos com o esporte, mas também para aqueles não envolvidos, uma vez que auxiliaria no combate aos preconceitos e estereótipos comumente associados à sua deficiência. 


\section{REFERÊNCIAS}

AMARAL, Lígia. Pensar a diferença/deficiência. Brasília: Coordenadoria Nacional para Integração da Pessoa Portadora de Deficiência, 1994.

AMARAL, Lígia. Sobre crocodilos e avestruzes: falando de diferenças físicas, preconceitos e sua superação. In: AQUINO, J. G. Diferenças e preconceitos na escola: alternativas teóricas e práticas. São Paulo: Summus, 1998. p. 01-30.

BRAGA, Adriana; GASTALDO, Édson. Variações sobre o uso do Skype na pesquisa empírica em comunicação: apontamentos metodológicos. Revista Contracampo, v. 1, n. 24, p. 4-18, 2012.

BRAUN, Virginia; CLARKE, Victoria. Using thematic analysis in psychology. Qualitative Research in Psychology, v. 3, n. 2, p. 77-101, 2006.

CAMBRUZZI, Giselda Maria Atzler Stophila. 0 discurso da mídia sobre a cobertura das paraolimpíadas de Pequim 2008 e a inclusão de pessoas com deficiência. 73f. Monografia (Especialização em Educação Inclusiva) - Centro de Educação a Distância, Universidade Estadual de Santa Catarina, Florianópolis, 2011.

FIGUEIREDO, Tatiane Hilgemberg; GUERRA, Marcio de Oliveira. Olimpíadas e Paraolimpíadas: uma correlação com a mídia. In: CONGRESSO BRASILEIRO DE CIÊNCIAS DA COMUNICAÇÃO, 28, 2005, Rio de Janeiro. Anais... Rio de Janeiro: UERJ, 2005. p. 1-10.

FIGUEIREDO, Tatiane Hilgemberg; NOVAIS, Rui Alexandre. Atletas com deficiências na mídia: a cobertura noticiosa dos jogos Paraolímpicos de Atlanta a Pequim nas imprensas portuguesa e brasileira. In: Anais eletrônicos..., São Paulo: USP, 2011. p. 1-14.

GOFFMAN, E. Estigma: notas sobre a manipulação da identidade deteriorada. 4.ed. Rio de Janeiro, LTC, 2008.

GONÇALVES, Gisele Carneirão; ALBINO, Beatriz Staimbach; VAZ, Alexandre. O herói esportivo deficiente: aspectos do discurso em mídia impressa sobre o Parapan-Americano 2007. In: PIRES, G de L. (Ed.). "Observando" o Pan Rio/2007 na mídia. Florianópolis: Tribo da llha, 2009.

HARDIN, Marie Myers; HARDIN, Brent. The "Superscript" in sport media: Wheelchair athletes discuss hegemony's disabled hero. SOSOL: Sociology of Sport Online, v. 7, n. 1, p. 1, 2004.

HELAL, Ronaldo; MARQUES, Ronaldo Galvão; CABO, Alvaro. Idolatria nos Jogos PanAmericanos de 2007: uma análise do jornalismo esportivo. Revista Contemporânea (UERJ. Online), v. 13, p. 33-43, 2009.

HILGEMBERG, Tatiane. Do Coitadinho ao Super-herói: Representação social dos atletas paraolímpicos na mídia brasileira e portuguesa. Ciberlegenda, n. 30, p. 48-58, 2014.

HOWE, David; JONES, Carwyn. Classification of disabled athletes: (Dis)empowering the Paralympic practice community. Sociology of Sport Journal, v. 23, n. 1, p. 29-46, 2006.

INSTITUTO BRASILEIRO DE GEOGRAFIA E ESTATÍSTICA (IBGE). Características gerais da população, religião e pessoas com deficiência. 2010. Disponível em: <https://biblioteca.ibge. ov.br/visualizacao/periodicos/94/cd 2010 religiao deficiencia.pdf>. Acesso em: 20 set.2018. 
LE BRETON, David. A sociologia do corpo. Petrópolis: Vozes, 2006.

MARQUES, Renato Francisco Rodrigues. 0 esporte paraolímpico no Brasil: abordagem da sociologia do esporte de Pierre Bourdieu. 2010. 286 f. Tese (Doutorado) - Faculdade de Educação Física, Universidade Estadual de Campinas, Campinas, 2010.

MARQUES, Renato Francisco Rodrigues. et al. A abordagem midiática sobre o esporte paralímpico: o ponto de vista de atletas brasileiros. Movimento, v. 20, n. 3, p. 989-1015, 2014.

MARQUES, Renato Francisco Rodrigues et al. A abordagem midiática sobre o desporto paralímpico: perspectivas de atletas portugueses. Motricidade, v. 11, n. 3, p. 123-147, 2015.

MARQUES, Renato Francisco Rodrigues. A contribuição dos Jogos Paralímpicos para a promoção da inclusão social: o discurso midiático como um obstáculo. Revista USP, n. 108, p. 87-96, 2016.

MARTíN-BARBERO, Jesus. Dos meios às mediações. Comunicação, cultura e hegemonia. Rio de Janeiro, Editora UFRJ, 2009.

MIRANDA, Tatiane Jacusiel. Comitê Paralímpico Brasileiro: 15 anos de história. 2011. 331 f. Dissertação (Mestrado) - Programa de pós-graduação em Educação Física. UNICAMP, Campinas, 2011.

MORATO, Marcio Pereira et al. A leitura do jogo no futebol para cegos. Movimento, v. 17, n. 3 , p. 97-114, 2011.

OLIVEIRA, Marta Olivia Rovedder et al. Uma comparação entre entrevistas face-to-face e entrevistas on-line via chat aplicando a técnica de laddering. Gestão \& Regionalidade, v. 25, n. 75, p. 57-72, 2010.

PIRES, Giovani de Lorenzo. Breve introdução ao estudo dos processos de apropriação social do fenômeno esporte. Journal of Physical Education, v. 9, n. 1, p. 25-34, 1998.

PURDUE, David; HOWE, David. See the sport, not the disability: exploring the Paralympic paradox. Qualitative research in sport, exercise and health, v. 4, n. 2, p. 189-205, 2012.

SANTOS, Silvan Menezes dos et al. Mídia e Jogos Paralímpicos no Brasil: a cobertura da Folha de S. Paulo entre 1992 e 2016. Revista Brasileira de Ciências do Esporte, 2018. Disponível em: <https://doi.org/10.1016/j.rbce.2018.03.012>. Acesso em: 05 dez. 2018.

SILVA, Carla Filomena; HOWE, David. The (In)validity of Supercrip Representation of Paralympian Athletes. Journal of Sport \& Social Issues, v. 36, n. 2, p. 174-194, 2012. 